\title{
Electrochemotherapy: first objective quality assessment of online information on a rising low-invasive procedure, in a constantly aging society
}

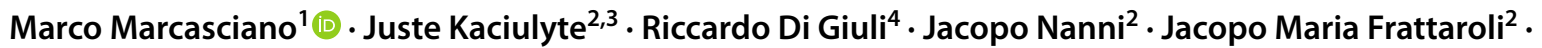 \\ Leonardo Garutti ${ }^{3,5} \cdot$ Federico Lo Torto $^{2} \cdot$ Paolo Fioramonti $^{2} \cdot$ Diego Ribuffo $^{2} \cdot$ Donato Casella $^{1}$
}

Received: 30 August 2021 / Accepted: 25 November 2021 / Published online: 27 January 2022

(c) The Author(s), under exclusive licence to Springer-Verlag GmbH Germany, part of Springer Nature 2021

Web development brought new scenarios in doctor-patient communication. Health professionals are no more the only vessel of medical knowledge and patients have new channels to explore in search for medical information. Technology and interconnection permeate our daily life and Internet became a major seeking information tool for the patients [1]. The constant increase of online reports and lack of verification made the quality of the available information the main issue [1].

During the pandemic, most hospitals had to reschedule their activities to ensure maximum availability of care for patients suffering from diseases related to SARS-CoV-2 and limitations to the access and hospital stays proved to be mandatory in order to reduce infectious risks. Considering the limited time of medical appointments, it appears natural that patients cannot exhaust all doubts at doctor's presence.

Furthermore, many of those who have just received an oncological diagnosis usually are not in the mental status to focus on the discussion. Worries, fears, and anxiety may

Marco Marcasciano

dott.marcomarcasciano@gmail.com

1 UOC Chirurgia Oncologica Della Mammella, Department of Breast Cancer Surgery, Azienda Ospedaliero-Universitaria Senese, University Hospital of Siena, Viale Mario Bracci, 16, 53100 Siena, Italy

2 Unit of Plastic and Reconstructive Surgery, Department of Surgery "P.Valdoni”, Policlinico Umberto I, Sapienza University of Rome, Rome, Italy

3 Department of Plastic Surgery, China Medical University and China Medical University Hospital, Taichung, Taiwan

4 Unit of Plastic and Reconstructive Surgery, Santa Maria Della Misericordia Hospital, University of Perugia, Perugia, Italy

5 Department of Biotechnology and Life Sciences, Division of Plastic and Reconstructive Surgery, University of Insubria, Varese, Italy often induce a sort of "shock," disabling people to formulating doubts and questions [2].

As a consequence, a significant amount of unclear or limited information is gathered on web portals by a majority of patients unable to discriminate about reliable sources, resulting in confusion or wrong expectations in such a delicate pandemic scenario and oncological setting.

In this regard, we investigated the quality of online information about electrochemotherapy (ECT), an oncological treatment to enhance the cellular uptake of hydrophilic drugs such as bleomycin and cisplatin, by exposing selected tissues to electric pulses [3]. It greatly increases the cytotoxicity and simultaneously limits the side effects to tissues, maximizing the therapeutic index. Such characteristics extended its application to multiple fields in plastic surgery, addressing different varieties of skin cancers, head and neck cutaneous metastasis, breast tumors, internal organs' non-cutaneous metastasis, and primary skin tumors not amenable for surgery [4].

Success rate varies in regard to the pathology treated and patient's population with values between 40 and $100 \%$ [3, 4].

In an aging society with a constantly increasing prevalence of elderly fragile people, patients being scheduled for ECT are often old, frail with multiple comorbidities, and diagnosed with non-surgical tumors and palliative indication. The switch in intention from curative to palliative in order to safeguard patient's quality of life represents a significant step and surgeons must face the challenge to adapt to this concept.

In such a scenario, we deeply assessed the web applying the expanded version of Ensuring Quality Information Patients (EQIP) test, in order to evaluate the quality of online available information on ECT [5]. Data was collected during Pandemic March 2021. Google ${ }^{\circledR}$ and Yahoo ${ }^{\circledR}$, as the most common search engines, were selected to probe for the keywords "Electrochemotherapy 
AND Skin cancer" and "Electrochemotherapy AND Skin metastases" and "Electrochemotherapy AND Melanoma." The research identified 14 suitable websites according to EQIP tool criteria. Seven $(50 \%)$ belonged to healthcare portals, $5(36 \%)$ to professional societies, $1(7 \%)$ to hospitals, $1(7 \%)$ to encyclopedias, and none to practitioners. EQIP test outcomes are reported in Table 1, with a score ranging from 0 to 36 points. Good-quality websites were considered with scoring equal or higher than 20. Average result was 19.57 (range 14-23 points). The highest score was achieved by the hospital group with 22 , encyclopedias with 20, and healthcare portals with 20.7; the lowest score was obtained by professional societies with 17.4. Eight websites $(57 \%)$ presented a high score, and $6(43 \%)$ scored less than 20. Results reported a lack of detailed information regarding ECT and its applications.

The totality of the sites described the technique outcomes in its qualitative characterization but only $36 \%$ supplied
Table 1 Google $\AA$ and Yahoo®, as the most common search engines, were selected to probe for the keywords "Electrochemotherapy AND Skin cancer" and "Electrochemotherapy AND Skin metastases" and "Electrochemotherapy AND Melanoma." The research identified only 14 suitable websites according to EQIP tool criteria. The table reports the outcomes in detail

\begin{tabular}{|c|c|c|}
\hline Question & Yes $(\%)$ & No $(\%)$ \\
\hline \multicolumn{3}{|l|}{ Content data } \\
\hline 1. Initial definition of which subjects will be covered & $14(100 \%)$ & $0(0 \%)$ \\
\hline 2. Coverage of the above-defined subjects & $14(100 \%)$ & $0(0 \%)$ \\
\hline 3. Description of the medical problem & $14(100 \%)$ & $0(0 \%)$ \\
\hline 4. Definition of the purpose of the medical intervention & $14(100 \%)$ & $0(0 \%)$ \\
\hline 5. Description of treatment alternatives (including no treatment) & $4(28.57 \%)$ & $10(71.43 \%)$ \\
\hline 6. Description of the sequence of the medical procedure & $12(85.71 \%)$ & $2(14.29 \%)$ \\
\hline 7. Description of qualitative benefits & $14(100 \%)$ & $0(0 \%)$ \\
\hline 8. Description of quantitative benefits & $5(35.71 \%)$ & $9(64.29 \%)$ \\
\hline 9. Description of qualitative risks and side-effects & $12(85.71 \%)$ & $2(14.29 \%)$ \\
\hline 10. Description of quantitative risks and side-effects & $1(7.14 \%)$ & $13(92.86 \%)$ \\
\hline 11. Addressing quality of life issues & $5(35.71 \%)$ & $9(64.29 \%)$ \\
\hline 12. Description of how potential complications will be dealt with & $7(50 \%)$ & $7(50 \%)$ \\
\hline 13. Description of precautions that the patient may take & $1(7.14 \%)$ & $13(92.86 \%)$ \\
\hline 14. Mention of alert signs that the patient may detect & $4(28.57 \%)$ & $10(71.43 \%)$ \\
\hline 15. Addressing medical intervention cost and insurance issues & $1(7.14 \%)$ & $13(92.86 \%)$ \\
\hline 16. Specific contact details for hospital services & $3(21.43 \%)$ & $11(78.57 \%)$ \\
\hline 17. Specific details of other sources of reliable information/support & $5(35.71 \%)$ & $9(64.29 \%)$ \\
\hline 18. The document covers all relevant issues on the topic & $0(0 \%)$ & $14(100 \%)$ \\
\hline \multicolumn{3}{|l|}{ Identification data } \\
\hline 19. Date of issue or revision & $11(78.57 \%)$ & $3(21.43 \%)$ \\
\hline 20. Logo of the issuing body & $14(100 \%)$ & $0(0 \%)$ \\
\hline 21. Name of persons or entities that produced the document & $8(57.14 \%)$ & $6(42.86 \%)$ \\
\hline 22. Name of persons or entities that financed the document & $3(21.43 \%)$ & $11(78.57 \%)$ \\
\hline 23. Short bibliography of evidence-based data used in the document & $5(35.71 \%)$ & $9(64.29 \%)$ \\
\hline $\begin{array}{l}24 \text {. The document states if and how patients were involved/consulted in its } \\
\text { production }\end{array}$ & $0(0 \%)$ & $14(100 \%)$ \\
\hline \multicolumn{3}{|l|}{ Structure data } \\
\hline 25. Use of everyday language, explains complex words or jargon & $8(57.14 \%)$ & $6(42.86 \%)$ \\
\hline 26. Use of generic names for all medications or products & $12(85.71 \%)$ & $2(14.29 \%)$ \\
\hline 27. Use of short sentences & $9(64.29 \%)$ & $5(35.71 \%)$ \\
\hline 28. The document personally addresses the reader & $7(50 \%)$ & $7(50 \%)$ \\
\hline 29. The tone is respectful & $14(100 \%)$ & $0(0 \%)$ \\
\hline 30. Information is clear & $14(100 \%)$ & $0(0 \%)$ \\
\hline 31. Information is balanced between risks and benefits & $6(42.86 \%)$ & $8(57.14 \%)$ \\
\hline 32. Information is presented in a logical order & $12(85.71 \%)$ & $2(14.29 \%)$ \\
\hline 33. The design and layout are satisfactory & $12(85.71 \%)$ & $2(14.29 \%)$ \\
\hline 34. Figures or graphs are clear and relevant & $6(42.86 \%)$ & $8(57.14 \%)$ \\
\hline 35. The document has a named space for the reader's notes & $3(21.43 \%)$ & $11(78.57 \%)$ \\
\hline 36. The document includes a consent form, contrary to recommendations & $0(0 \%)$ & $14(100 \%)$ \\
\hline
\end{tabular}


Fig. 1 The graphic shows the chronological assessment of published papers concerning electrochemotherapy since the first clinical trial in 1991. An increasing trend of dedicated articles is evidenced, with a total of 1141 publications to date

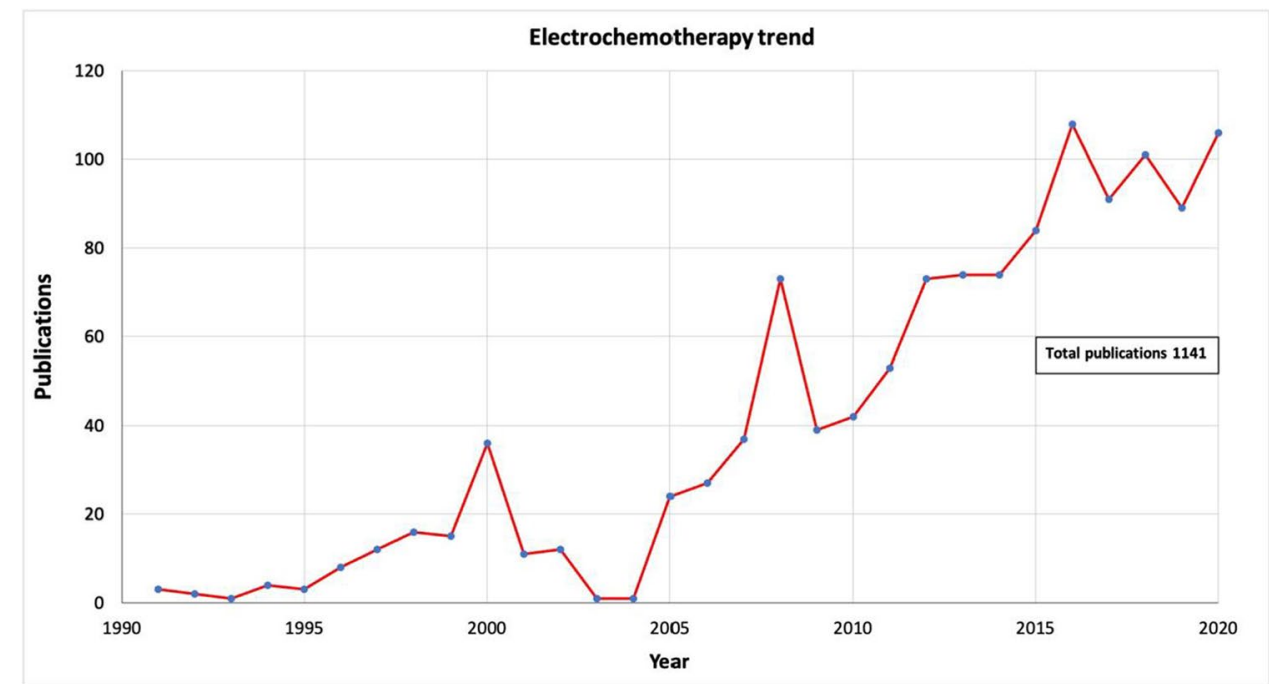

quantitative reports. Risks were often mentioned (86\%) but they were hardly quantified (7\%) providing an off-balance view of the technique. None of the sites resulted adequately in covering thoughtfully the relevant topic about the technique. More than $50 \%$ of them resulted unbalanced between risks and benefits, providing unclear or irrelevant figures. Moreover, concrete quantitative reports such as success rate were supplied in only one-third of the cases. Only 14 websites were worthy of consideration in providing information to the public, unveiling a quantitative as well qualitative lack of reliable informative sources for the patients. On the other hand, the chronological review of PubMed database on ECT highlighted an increasing number of dedicated articles, with a total of 1.141 publications since 1991 (Fig. 1).

As ECT employment gains in diffusion, more patients are proposed with such a highly selective procedure that it is still not fully acknowledged. We registered a deep contrast between the rising trend in electrochemotherapy and dangerous lack of reliable and comprehensive online informative websites for patients, calling a need for good-quality online information.

As far as we know, this is the first investigation focusing on online information quality regarding ECT. Wrong information from unreliable sources could expose patients to fake news and false ideologies potentially affecting their judgment, misleading them towards ineffective treatments with subsequent time loss and reduced quality of life.

\section{Declarations}

Ethical approval No ethical approval was required for this study. This article does not contain any studies involving human participants or animals performed by any of the authors.
Informed consent No informed consent was required.

Conflict of interest Marcasciano M, Kaciulyte J, Di Giuli R, Nanni J, Frattaroli JM, Garutti L, Cherubino M, Lo Torto F, Fioramonti P, Ribuffo D, and Casella D declare no competing interests.

\section{References}

1. Goto Y, Nagase T (2012) Oncology information on the internet. Jpn J Clin Oncol 42:368-374

2. Taylor BH, Warnock C, Tod A (2019) Communication of a mesothelioma diagnosis: developing recommendations to improve the patient experience. BMJ Open Respir Res 6:e000413

3. Gehl J, Sersa G, Matthiessen LW, Muir T, Soden D, Occhini A, Quaglino P, Curatolo P, Campana LG, Kunte C, Clover AJP, Bertino G, Farricha V, Odili J, Dahlstrom K, Benazzo M, Mir LM (2018) Updated standard operating procedures for electrochemotherapy of cutaneous tumours and skin metastases. Acta Oncol 57:874-882

4. Guida M, Campana LG, Curatolo P, Strippoli S, Bonadies A, Grilz G, Cabula C, Rotunno R, Bucher S, Solari N, Santoriello A, Valpione S, Rossi CR (2016) Local treatment with electrochemotherapy of superficial angiosarcomas: efficacy and safety results from a multi-institutional retrospective study. J Surg Oncol 114:246-253

5. Marcasciano M, Frattaroli J, Mori FLR, Lo Torto F, Fioramonti P, Cavalieri E, Kaciulyte J, Greco M, Casella D, Ribuffo D (2019) The new trend of pre-pectoral breast reconstruction: an objective evaluation of the quality of online information for patients undergoing breast reconstruction. Aesthetic Plast Surg 43:593-599

Publisher's note Springer Nature remains neutral with regard to jurisdictional claims in published maps and institutional affiliations. 